\title{
Jogos Cooperativos: uma proposta inovadora para o ensino da Educação Ambiental
}

\author{
Hugo da Silva Florentino ${ }^{1,2}$, Laryssa Abílio Oliveira ${ }^{2}$ \& Francisco José Pegado \\ Abílio $^{2}$
}

(1) Universidade Federal de Campina Grande, Centro de Formação de Professores, Unidade Acadêmica de Ciências Exatas e da Natureza, Rua Sérgio Moreira de Figueiredo, Casas Populares, Cajazeiras 58900000, Paraíba, Brasil. E-mail: hugoxtr@hotmail.com

(2) Universidade Federal da Paraíba, Centro de Educação, Programa de Pós-Graduação em Educação, Cidade Universitária, Castelo Branco III, João Pessoa 58051-900, Paraíba, Brasil. E-mail: chicopegado@yahoo.com.br

Florentino H.S., Oliveira L.A. \& Abílio F.J.P. (2017) Jogos Cooperativos: uma proposta inovadora para o ensino da Educação Ambiental. Pesquisa e Ensino em Ciências Exatas e da Natureza, 1(2): 166-178.

Resumo: Este artigo descreve a experiência na construção, aplicação e avaliação de um jogo de tabuleiro cooperativo baseado na Carta da Terra. Trata-se de um estudo qualitativo, do tipo exploratório-descritivo, desenvolvido e validado com alunos/as de diferentes níveis de ensino de uma escola pública do município de João Pessoa-PB. Os resultados indicaram que o jogo teve uma avaliação positiva na aceitação e satisfação dos/as alunos/as, sendo uma proposta inovadora, dinâmica e criativa para se trabalhar a educação ambiental em diferentes níveis de ensino, pois permite que sejam trabalhados não apenas questões ambientais, mas questões sociais, éticas, políticas, econômicas e culturais de forma cognitiva, afetiva, criativa e reflexiva, promovendo simultaneamente o desenvolvimento de conhecimento, de atitudes e de habilidades necessárias à construção de uma sociedade sustentável.

Palavras chave: Educação Ambiental, Carta da Terra, jogos cooperativos.

\section{Cooperative Games: an innovative proposal for the teaching of Environmental Education}

Abstract: This article describes the experience of construction, implementation and evaluation of a cooperative board game named "RCT Game" based on the Earth Charter. This is a qualitative study, based on an exploratory and descriptive approach. It was developed and validated with students of different levels of education in a public school in the municipality of João Pessoa, Paraiba. The results indicated that the game had a positive evaluation in the acceptance and satisfaction of the students, being an innovative, dynamic and creative proposal to work on environmental education at different levels of education, as it allows to work not only environmental issues but also social, ethical, political, economic, and cultural issues in a cognitive, affective, creative and reflexive way, while promoting the development of knowledge, attitudes and skills needed to build a sustainable society.

Key words: Environmental Education, Earth Charter, cooperative games.

\section{Introdução}

A problemática da sustentabilidade assume, nesta última década, um papel fundamental na reflexão sobre a relação ser humano, sociedade, ambiente (natureza) e, consequentemente, nas dimensões do desenvolvimento socioambiental que caracteriza as sociedades contemporâneas (Jacobi 2003), não sendo possível ponderar sob o viés econômico ou ambiental, mas numa interdependência potencializadora entre as múltiplas dimensões que envolvem questões ambientais e econômicas com sociais, éticas, políticas e culturais (Gadotti 2010).

Leff (2001) aponta que é impossível resolver os crescentes e complexos problemas socioambientais e reverter suas causas sem que ocorram mudanças nos sistemas de 
conhecimento, dos valores e dos comportamentos gerados pela dinâmica de racionalidade existente, fundada no aspecto econômico do desenvolvimento.

Repensar a relação ser humano, sociedade e ambiente em suas múltiplas dimensões (ética, social, cultural, política, ambiental, econômica) e intersubjetividades (emoção e ludicidade) é apontada como uma das possibilidades de reverter este quadro que amargura a sociedade. Para tanto, Jacobi (2003) assinala a Educação Ambiental como estratégia basilar para tal mudança, pois desperta a consciência crítica e a sensibilização para o desenvolvimento de atitudes e condutas que favoreçam o exercício da cidadania, do respeito, do cuidado, da afetividade e de uma nova relação equilibrada com o ambiente.

Com a Educação Ambiental é possível construir um processo de ressignificação do modo de "pensar" e "agir" na tríplice "no", "para" e "com" o ambiente (Loureiro 2007), apontando outro caminhar individual e coletivo. Como afirma Grun (1996: 22), "o indivíduo deve buscar ressignificar sua relação com o meio ambiente e [...] resgatar alguns valores já existentes" e, com isso, construir uma nova forma [de] aprender a ser, fazer e conviver com o ambiente.

A questão não é somente conhecer para se ter consciência de algo, mas, como afirma Loureiro (2007: 69), "conhecer inserido no mundo para que se tenha consciência crítica do conjunto de relações que condicionam certas práticas culturais e, nesse movimento, superarmonos e às próprias condições inicialmente configuradas".

Compreendemos, portanto, que a Educação Ambiental permite reflexões e atitudes que proporcionam a geração de uma nova e ativa "consciência" que aceite a sustentabilidade em um movimento de integração entre as partes, formando um todo, em interação constante humanoambiente, valorizando as instancias da razão, do sentimento, da afetividade e do prazer em consonância com as questões sociais, culturais, éticas, políticas, ambientais e econômicas (Dias 2003).

Dentre os documentos que podem direcionar um processo de Educação Ambiental nos moldes da sustentabilidade destacamos a Carta da Terra (2007) que, inspirada em diversas fontes (como a ciência contemporânea, as tradições éticas, religiosas e filosóficas do mundo e os saberes e fazeres dos povos que vivem e convivem com a sustentabilidade), promove uma reaproximação entre a tríplice ser humano, sociedade e ambiente em um processo de interrelação e interdependência entre o "eu" e o "outro", no resgate de princípios e valores que orientam a "práxis" da sustentabilidade.

Entretanto, para o desenvolvimento de práticas de Educação Ambiental no contexto escolar, não basta conhecer teoricamente os princípios da Carta da Terra que orientam a Educação Ambiental. É necessário que a escola supere os limites do ensino tradicionalista e, com isso, estimule os sujeitos educativos a uma "práxis" educativa que envolva a reflexão e a ação.

Considerando que não há desenvolvimento cognitivo sem o envolvimento do sujeito com o objeto, os jogos cooperativos se apresentam como uma possibilidade de envolvimento do ser humano com práticas transformadoras, aproximando teoria da prática e exercitando a reflexão, o diálogo, a autonomia e a criatividade, pois são os/as alunos/as que discutem e constroem o seu próprio conhecimento (Vasconcellos 2004).

Embora qualquer jogo possa ser adaptado e utilizado como facilitador e elemento motivador no contexto escolar, ao se trabalhar os princípios e valores da Carta da Terra é interessante que se desenvolvam habilidades a exemplo da solidariedade e cooperação, pouco enfatizadas nos jogos competitivos tradicionais. Precisamos escolher um jogo que "propicie uma reflexão de nossa postura diante da vida e de si mesmo, e para tanto precisamos pensar como queremos estar no jogo? Mais próximo ou mais distante, sozinho ou em grupo, aberto ou fechado, egoísta ou solidário" (Bechelli 2005: 68).

A utilização de jogos cooperativos seria uma proposta inovadora e dinâmica para se trabalhar os princípios e valores da Carta da Terra, pois permite que durante sua aplicação sejam trabalhadas posturas como solidariedade, fraternidade, respeito e confiança, tornando um instrumento de construção do bem-estar social e psicológico que são atitudes importantes para uma relação social e na mudança de posturas em relação ao ambiente. 
Objetivamos desenvolver um jogo de tabuleiro cooperativo baseado na Carta da Terra como instrumentação e estratégia para o desenvolvimento da Educação Ambiental Crítica em espaços escolares.

\section{Material e Métodos}

\section{Local e sujeitos da pesquisa}

A pesquisa foi desenvolvida no ano de 2014 com 60 discentes, sendo 18 aluno/as do $3^{\circ}$ ano do Ensino Médio, 21 da Educação de Jovens e Adultos - Ensino Médio e 21 do $9^{\circ}$ ano do Ensino Fundamental da Escola Estadual de Ensino Fundamental e Médio Pedro Lins Vieira de Melo, situada no município de João Pessoa-PB.

\section{Procedimentos metodológicos}

A abordagem metodológica deste estudo caracteriza-se por um estudo qualitativo, do tipo exploratório-descritivo. A pesquisa qualitativa, para Richardson (2007: 90), "pode ser caracterizada como a tentativa de uma compreensão detalhada dos significados e características situacionais apresentados pelos sujeitos envolvidos na pesquisa, em lugar da produção de medidas quantitativas de características ou comportamentos". É do tipo exploratória, pois proporciona maior familiaridade com o problema e tem por finalidade recolher e registrar sistematicamente os dados relativos ao assunto escolhido como objeto de estudo (Gil 2008) e também descritiva por usar dados ou fatos colhidos da própria realidade e têm como foco descrever de forma mais aprofundada os sujeitos inseridos em uma realidade (Triviños 2009).

\section{Instrumentos de coleta e análise dos dados}

Utilizamos como instrumento de coleta de dados questionários estruturados e observação participante. Para a observação, os dados foram anotados durante a aplicação do jogo "Reconstruindo a Carta da Terra" (RCT Jogo), tomando cuidado de observar situações comportamentais/atitudinais e de conhecimento de acordo com as orientações de Triviños (2009). Para os questionários, procedemos em duas etapas: (1) Questionário sobre a percepção do/a aluno/a antes e depois da realização do jogo, com o propósito de permitir uma análise comparativa entre as informações anteriores e posteriores à aplicação do jogo; (2) Questionário de Avaliação do Jogo, com a finalidade de identificar a satisfação e a efetividade em sala de aula.

Os dados coletados foram categorizados de acordo com os conteúdos (respostas) manifestados, ordenados por grupos e contabilizados por meio do grau de incidência em cada questão e, para os conceitos de Educação Ambiental expostos pelos/as alunos/as, utilizou-se as tipologias de Sauvé, adaptadas e ampliadas por Guerra \& Abílio (2006), a qual classifica as percepções sobre Educação Ambiental em 11 categorias (Generalista, Preservacionista, Conservacionista, Conscientização, Desenvolvimento Sustentável, Ecologista Ecossistêmica, Disciplina Curricular, Atividade Resolutiva, Prática Educativa Interdisciplinar, Socio-AmbientalCultural), conforme Tabela 1.

\section{O jogo Redescobrindo a Carta da Terra (RCT Jogo)}

Trata-se de um jogo de tabuleiro cooperativo baseado nos princípios e valores contidos na Carta da Terra (Carta da Terra 2007; Gadotti 2010), elaborado na tentativa de tornar-se um recurso didático para ser utilizado nas escolas de João Pessoa.

O tabuleiro do jogo foi construído com base numa representação artística da Educação Ambiental, onde a tradicional linearidade sequencial é substituída por uma trama circular complexa, formada pela interseç̧ão de círculos menores e o conteúdo abordado por meio de cartas (verde, vermelha, azul e marrom) elaboradas cuidadosamente a partir de situações cotidianas e problemas socioambientais que envolvem a cidade de João Pessoa. As regras do "RCT Jogo" é uma adaptação do jogo "A Carta da Terra" criada por Abuhab \& Blauth (2011). 
Tabela 1. Tipologias de classificação dos conceitos de Educação Ambiental. Fonte: Guerra \& Abílio (2006).

\begin{tabular}{|c|c|}
\hline Categoria conceitual de Educação Ambiental & Características \\
\hline Generalista & $\begin{array}{l}\text { Quando demonstra uma visão ampla e confusa sobre } \\
\text { conteúdos e/ou atividades de Educação Ambiental. }\end{array}$ \\
\hline Preservacionista & $\begin{array}{l}\text { Quando valoriza “em excesso" o processo de } \\
\text { preservação dos recursos naturais (manutenção dos } \\
\text { recursos naturais intocáveis ou para as gerações } \\
\text { futuras). }\end{array}$ \\
\hline Conservacionista & $\begin{array}{l}\text { Quando valoriza o processo de conservação dos } \\
\text { recursos naturais (os recursos naturais podem ser } \\
\text { explorados desde que seja utilizado de forma racional). }\end{array}$ \\
\hline Sensibilização & $\begin{array}{l}\text { Processos de formação do indivíduo que busca a } \\
\text { sensibilização quanto aos problemas ambientais e } \\
\text { utilização dos recursos ambientais de forma racional. }\end{array}$ \\
\hline Conscientização & $\begin{array}{l}\text { Processos de formação do indivíduo crítico e reflexivo e } \\
\text { que busca a conscientização quanto aos problemas } \\
\text { ambientais e utilização dos recursos ambientais de } \\
\text { forma racional. }\end{array}$ \\
\hline Desenvolvimento Sustentável & $\begin{array}{l}\text { Promoção de valores que mantenham os padrões de } \\
\text { consumo dentro do limite das possibilidades ecológicas } \\
\text { a que todos podem, de modo razoável aspirar; } \\
\text { minimizar impactos adversos sobre os recursos } \\
\text { naturais, a fim de manter a integridade global do } \\
\text { Ecossistema. }\end{array}$ \\
\hline Ecologista Ecossistêmica & $\begin{array}{l}\text { Quando demonstra uma confusão com a Ciência } \\
\text { Ecologia ou seus conceitos; ou quando se verifica que é } \\
\text { apenas no Ecossistema onde se deve desenvolver } \\
\text { atividade de Educação Ambiental. }\end{array}$ \\
\hline Disciplina Curricular & $\begin{array}{l}\text { Quando os diferentes atores sociais associam a } \\
\text { Educação Ambiental como uma disciplina curricular } \\
\text { ou "ensinar para o meio ambiente", etc. }\end{array}$ \\
\hline Atividade Resolutiva & $\begin{array}{l}\text { Quando demonstra que as atividades de Educação } \\
\text { Ambiental podem ou vão contribuir para "resolver" os } \\
\text { problemas ambientais. }\end{array}$ \\
\hline Prática Educativa Interdisciplinar & $\begin{array}{l}\text { Quando demonstra que haja interações entre } \\
\text { disciplinas, através de um planejamento integrado das } \\
\text { experiências de aprendizagem, para se desenvolver } \\
\text { atividades e/ou práticas educativas de Educação } \\
\text { Ambiental. }\end{array}$ \\
\hline Sócio-Ambiental-Cultural & $\begin{array}{l}\text { Quando considera o Meio Social e o Cultural inserido } \\
\text { no Ambiente Natural; Processo de formação- } \\
\text { informação e o desenvolvimento da consciência crítica } \\
\text { sobre as questões ambientais com a participação das } \\
\text { comunidades na conservação e manutenção do } \\
\text { equilíbrio ambiental. }\end{array}$ \\
\hline
\end{tabular}

\section{Resultados e Discussão}

\section{RCT Jogo: da idealização à construção}

A idealização do jogo foi um desafio no qual procuramos construir um jogo que apresentasse características cooperativas que exercitassem o diálogo, a reflexão, a autonomia, a criatividade e, sobretudo, envolvessem os participantes com os valores e princípios contidos na Carta da Terra de forma lúdica e prazerosa, fortalecendo as relações presentes na Educação Ambiental, pois é possível conhecer e vivenciar os princípios e valores da Carta da Terra de modo cognitivo, afetivo, criativo e reflexivo (Gramigna 2007). 
O primeiro passo foi decidir o tipo de jogo que seria mais adequado para trabalhar os princípios e valores da Carta da Terra. Baseados em Neves \& Pereira (2006), escolhemos o jogo de tabuleiro por apontar as seguintes características:

A interação entre as pessoas, o olho-no-olho, a diversão gerada pela presença de vários amigos em torno da mesa, seja um jogo educativo ou não. São essas características que fortalecem as relações professor-aluno, aluno-professor e aluno-aluno, e que, finalmente, acabarão por fortalecer as relações do binômio ensino/aprendizagem (Neves \& Pereira 2006: 101).

Assim, surgiu o "RCT Jogo", um jogo de tabuleiro cooperativo onde "vencer" é entendido como "vencer com o outro", ao invés de "vencer o outro", tendo como objetivo proporcionar aos/às participantes a oportunidade de vivenciar os quatro princípios orientadores da Carta da Terra: I - Respeitar e Cuidar da Comunidade de Vida; II - Integridade Ecológica; III- Justiça Social e Econômica; IV - Democracia, Não violência e Paz (Carta da Terra 2007).

$\mathrm{O}$ jogo contém um tabuleiro circular de $1.70 \times 1.70 \mathrm{~m}$ de diâmetro confeccionado em tecido algodão cru e pintado com tinta acrílica para artesanato (Figura 1A); 01 (um) dado de seis faces com 14.5 x $14.5 \mathrm{~cm}$ de dimensão, confeccionado em papelão; e 01 (um) conjunto de 04 (quatro) baralhos de cartas (vermelha, verde, azul e marrom) distribuídas em 18 (dezoito) cartas verdes, 18 (dezoito) cartas vermelhas, 18 (dezoito) cartas azuis e 32 (trinta e duas) cartas marrons, além de 04 (quatro) "cartas-segredos", representadas pelos elementos: água, ar, fogo e terra (Figura 1).

O Baralho Verde representa as atitudes consideradas éticas, podendo ser individual ou coletiva, nas quais os/as participantes vivenciarão posturas que contribuam para a (re)construção de uma sociedade ética, justa e igualitária (Figura 1B).

O Baralho Azul simula palavras-chave sobre conteúdos trabalhados na Carta da Terra como: natureza, amor, cooperação, justiça, saúde, cidadania, respeito, reutilização, minoria, reciclagem, solidariedade, preconceito, violência, pobreza, entre outros, onde os/as participantes deverão expor os sentimentos e opiniões e, posteriormente, construirão um conceito coletivo, relacionando ao conteúdo valores e atitudes contidas na Carta da Terra (Figura 1C).

O Baralho Marrom concebe as atividades sensório-motoras que devem ser executadas pelo grupo. Consiste de ações que estimulam a percepção do "meio" e do "outro" de forma lúdica, sensorial e motora, onde os/as participantes utilizam o próprio corpo para a produção de sons, movimentos e situações reflexivas (Figura 1D).

O Baralho Vermelho representa problemas socioambientais e ético-culturais. Com ele os/as jogadores/as vivenciam atitudes e situações que prejudicam o ambiente e sua sociobiodiversidade (Figura 1E).

As Cartas-segredo contêm os 04 (quatro) elementos da natureza: água, fogo, terra e ar, e representam um momento de integração do grupo e etapa obrigatória para chegar ao fim do jogo que denominaremos como "(re)começo", onde os/as participantes celebrarão a conquista por meio de um desenho coletivo sobre sua vivência e aprendizagens durante o jogo (Figura 1F).

\section{As regras do RCT jogo}

O jogo inicia-se com a escolha das peças que pode ser qualquer objeto que o/a participante tenha afinidade para representá-lo/a. Na sequência, cada participante ou grupos de participantes (caso joguem mais de 06 jogadores) recebem 06 (seis) sementes que representarão a energia de sobrevivência do/a participante durante o jogo. Essa Fonte de Energia, localizada no centro do tabuleiro (recomeço), é colocada uma quantidade de sementes igual a 06 (seis) vezes 0 número de jogadores/as (exemplo: para 05 (cinco) participantes coloca-se 30 (trinta) sementes na fonte de energia).

Cada jogador/a, na sua vez, entrega uma semente para a fonte de energia, joga o dado e avança com o cone o número indicado de casas, podendo se movimentar em todas as direções. Na casa onde o cone parar, o/a participante deverá retirar uma carta do baralho, da mesma cor 
correspondente ao tabuleiro e ler em voz alta para o grupo. No caso do/a participante cair na casa verde, além da carta dessa cor, o/a jogador/a deverá também pegar uma carta do baralho marrom. Dependendo da carta, o/a participante ganha ou perde pontos e sementes. A carta escolhida não volta para o baralho durante o jogo.

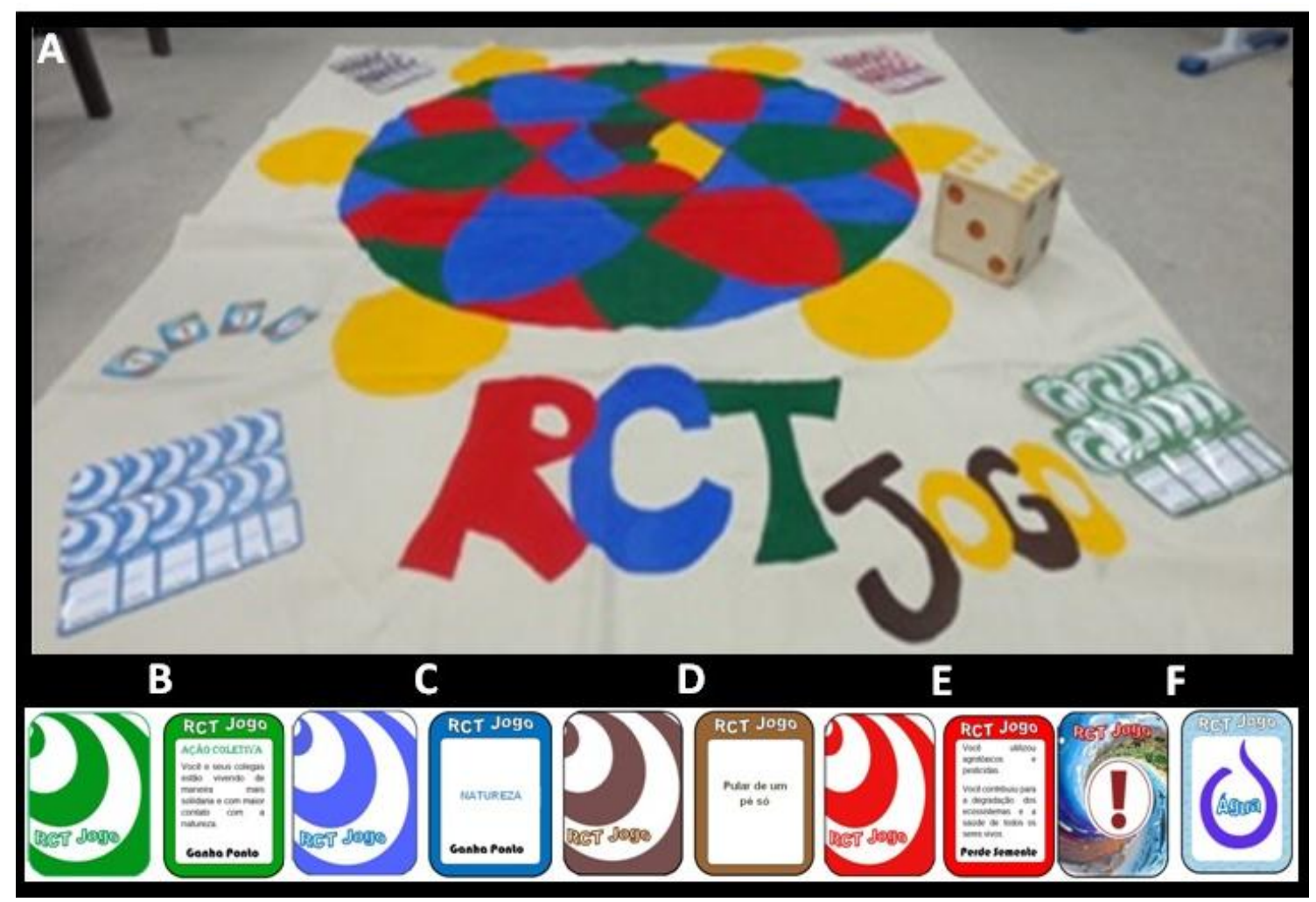

Figura 1. RCT Jogo e seus componentes: (A) tabuleiro, (B) carta verde, (C) carta azul, (D) carta marrom, (E) carta vermelha, (F) carta segredo.

Os/as participantes ganham o jogo se todos atravessarem o Território em direção ao (re)começo. Nesse momento, devem ter em sua posse as 04 (quatro) Cartas-segredos que possibilitam atravessar o território místico e chegar ao (re)começo. Os/as participantes perdem o jogo se a fonte de energia ou eles/as ficarem sem sementes ou, ainda, se no momento da travessia faltar uma das 04 (quatro) cartas-segredos. Assim, antes de ingressarem no território místico, os/as jogadores/as devem percorrer o jogo de tabuleiro em busca das Cartas-segredos e ficar atentos/as se aos/às colegas (ou grupos) conseguiram cumprir todas as etapas estabelecidas.

As Cartas-segredo serão conquistadas ao longo das travessias das casas- no mínimo 02 (duas) vezes a cor de cada casa e somar 06 (seis) pontos- numa viagem pelos problemas socioambientais, das situações do dia-a-dia (individuais e coletivas) e das ações sensório-motoras.

Os/as participantes, durante o jogo, devem cooperar uns com os outros para que juntos consigam conquistar as Cartas-segredos e manter o equilíbrio energético entre o/a jogador/a (o homem ou a mulher) e o tabuleiro (ambiente), representado pela fonte de energia. Mesmo que o/a participante cumpra todas as etapas previstas e consiga as 04 (quatro) Cartas-segredo, continua jogando e tendo que cooperar com os outros para que consigam também cumprir os objetivos, pois, por se tratar de um jogo cooperativo todos precisam chegar ao final juntos para poderem vencer ou, então, todos perdem.

Por fim, o jogo poderá ser desenvolvido em sala de aula ou em qualquer espaço educativo por no mínimo 04 (quatro) participantes ou de acordo com o tamanho da turma. Neste último caso, o mediador do jogo (o/a docente) deverá dividir a sala em até 06 (grupos), por exemplo: se jogarem 18 (dezoito) participantes, a turma será agrupada em 06 (seis) grupos de 03 (três) participantes cada. 


\section{Percepção Socioambiental dos/as Alunos/as: um olhar antes e depois do jogo}

Considerando que as percepções refletem as experiências vividas por cada sujeito, e que os estudos de percepção fornecem um significativo entendimento das interações, sentidos, sentimentos, hábitos e valores que o sujeito estabelece com o ambiente (Tuan 2012), conhecer a forma como os/as alunos/as percebem a temática ambiental antes e depois da aplicação do jogo possibilita uma melhor compreensão do processo de mudança de posturas e valores, bem como um direcionamento de práticas educativas de enfoque sustentável.

Ao perguntar sobre a definição de Educação Ambiental, a maioria dos/as alunos/as (EJA, Ensino Fundamental e Médio), antes da aplicação do jogo (pré-teste), não soube definir o termo (54.5\% EJA, $71.4 \%$ E. Fundamental e $33.3 \%$ E. Médio) e/ou demonstram uma visão naturalista e restrita à "práticas resolutivas", quando demonstra que as práticas de Educação Ambiental contribuíram para "resolver" os problemas ambientais ou valorizar o processo de conservação e/ou preservação dos recursos naturais (Tabela 2).

Por outro lado, após a aplicação do jogo, muito embora vários/as alunos/as continuassem a afirmar não saber o que é Educação Ambiental ou dar ênfase a aspectos naturalistas, uma grande maioria passou a considerar a educação para além da dimensão, incorporando o meio social, cultural ao ambiental e natural, conforme as respostas de 18,2\% dos/as discentes da EJA, 21.4\% do Ensino Fundamental e 16.7\% do Médio (Tabela 2).

Tabela 2. Percepção, em porcentagem, dos/as alunos/as do EJA, Ensino Fundamental e Médio sobre o conceito de Educação Ambiental antes e depois da aplicação do "RCT Jogo".

\begin{tabular}{lcccccc}
\hline \multirow{2}{*}{ Categoria Conceitual } & \multicolumn{2}{c}{ EJA } & \multicolumn{2}{c}{ Ensino Fundamental } & \multicolumn{2}{c}{ Ensino Médio } \\
\cline { 2 - 7 } Preservacionista & Pré-teste & Pós-teste & Pré-teste & Pós-teste & Pré-teste & Pós-teste \\
Prática Resolutiva & - & - & $7.1 \%$ & $21.4 \%$ & - & - \\
Disciplina Curricular & $27.3 \%$ & $18.2 \%$ & $21.4 \%$ & - & - & - \\
Conscientização & - & $18.2 \%$ & - & $28.6 \%$ & $41.7 \%$ & $33.33 \%$ \\
Generalista & - & $9.1 \%$ & - & $14.3 \%$ & $8.3 \%$ & $16.7 \%$ \\
Conservacionista & $9.1 \%$ & - & - & - & $16.7 \%$ & - \\
Sócio-Ambiental-Cultural & $9.1 \%$ & $18.2 \%$ & - & - & - & $16.7 \%$ \\
Não Sabe & - & $18.2 \%$ & - & $21.4 \%$ & - & $16.7 \%$ \\
\hline
\end{tabular}

Os resultados da percepção após a aplicação do jogo demonstram que a participação em situações vivenciais proporciona uma reflexão sobre os problemas socioambientais e éticoculturais que não podem ser vividos unidimensionalmente, mas, sobretudo, em um processo de reintegração do ser humano ao ambiente.

Oliveira (2004) afirma que ao trabalhar com jogos, o problema passa a ser visto não mais como algo que inspira temor, levando ao afastamento ou à busca de auxílio externo para resolvê-lo, mas configura-se como algo fascinante e instigante, despertando a atenção, o raciocínio e a autonomia, além de resultados notáveis visualizados através da mudança de concepção em relação ao conceito de Educação Ambiental.

Em relação ao documento a "Carta da Terra", todos os/as alunos/as (Ensino Fundamental, Médio e EJA), antes da aplicação do jogo, afirmaram não saber do que se trata. Após a aplicação, $60 \%$ da turma da EJA, 55\% do Ensino Fundamental e 52\% do Médio afirmaram conhecer, embora menos de $20 \%$ do alunado dos diferentes níveis de ensino conseguiram citar alguma definição (Figura 2), a exemplo da resposta de uma aluna do terceiro ano do Ensino Médio: "A carta da terra é um documento que ajuda a cuidar do meio ambiente e de nós mesmo".

Embora a Carta da Terra seja um documento criado há mais de uma década, na qual aponta a declaração e princípios fundamentais para a construção de uma sociedade global, justa, sustentável e pacífica no século XXI, muitas escolas desconhecem a sua existência, o que aponta a necessidade de adotá-la como referencial formativo relevante na escola para construção de um processo de aprendizagem para um mundo mais justo, sustentável e pacífico (Brasil 2006). 
Além do mais, o desconhecimento da Carta da Terra pode ser justificado pela ausência de vivências de Educação Ambiental na escola, onde 40\% dos/as discentes do EJA, 71.4\% do Ensino Fundamental e $76.9 \%$ do Médio afirmaram nunca ter participado de ações ambientais no espaço escolar. E entre os/as que jogaram, a coleta seletiva, reciclagem de materiais e projetos educativos sobre o Meio Ambiente foram ações das quais participaram; todavia, não citaram em qual disciplina/s e/ou nível de ensino.

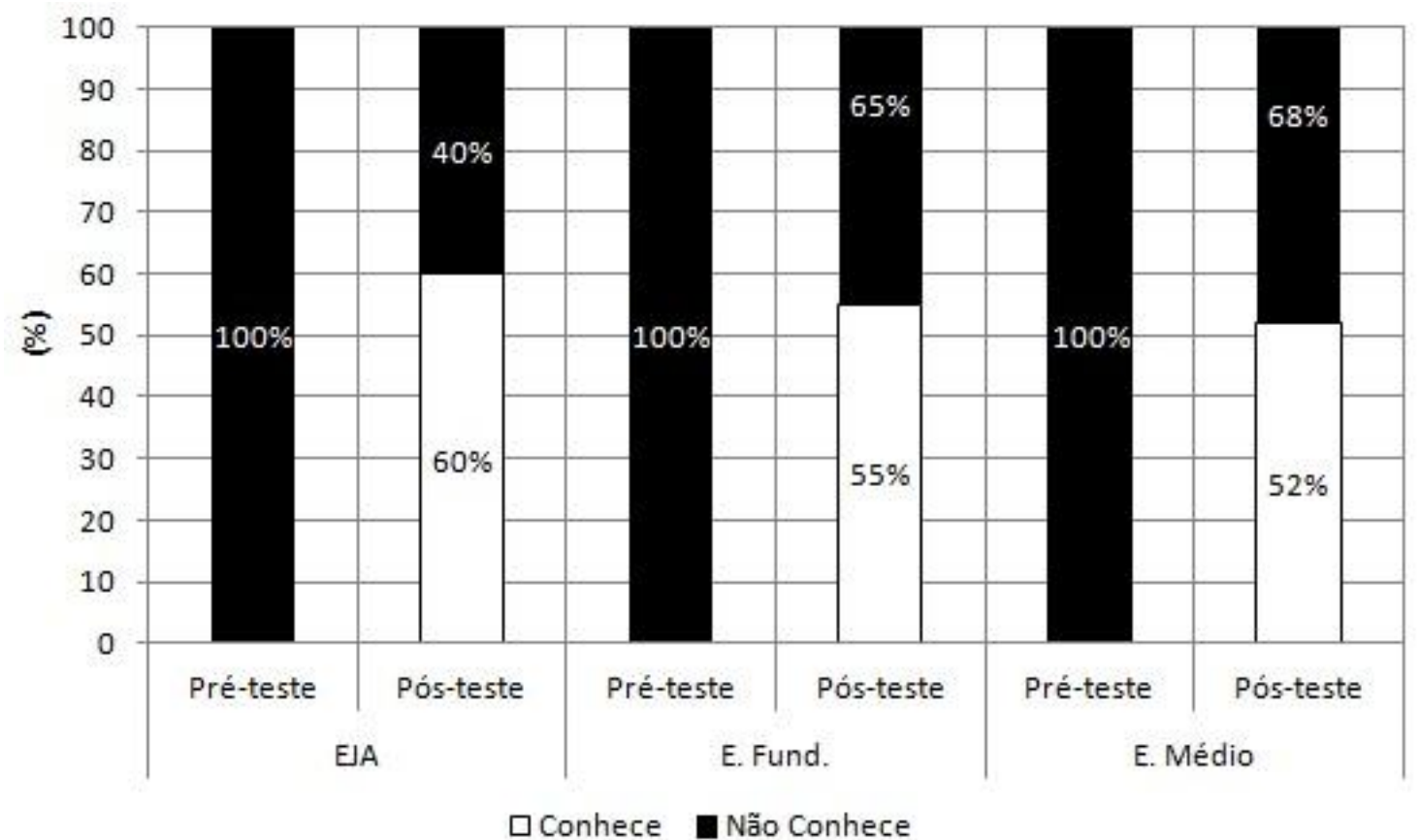

Figura 2. Percepção dos/as alunos/as da EJA, Ensino Fundamental e Médio sobre o conceito de Carta da Terra antes e depois da aplicação do "RCT Jogo".

Atualmente parece não ser mais possível afirmar que a escola desenvolve ações de Educação Ambiental apenas pelo fato de apresentar atuações de cunho ambiental, conservacionista. Entretanto, para compreender a complexidade da crise que atinge a sociedade e o ambiente, é necessário repensar posturas e valores, no sentido de construir um processo de síntese, jamais de separação.

Em relação aos impactos ambientais que ocorrem na cidade, antes da aplicação do jogo, $60 \%$ dos/as alunos/as da EJA, 28.6\% do Ensino Fundamental e 23.1\% do Médio afirmaram conhecer; contudo, apenas os/as alunos/as do Ensino Médio citaram os impactos: Poluição, lixo, queimadas, desmatamento, esgoto a céu aberto. Após a realização do "RCT Jogo", mais de 70\% dos/as discentes dos diferentes níveis passaram a dizer que conhecem os impactos ambientais que ocorrem no município de João Pessoa citando o lixo, as queimadas, o desmatamento, a caça predatória, construções irregulares, esgoto e queima de lixo.

Em seguida foi solicitado que marcassem as atividades, de acordo com a escala (muito, pouco, não prejudica) que degradam o meio ambiente. Os resultados demonstraram que o alunado da EJA apresenta maior sensibilidade e postura sustentável, uma vez que atribuiu ser muito importante, não apenas impactos ambientais (desmatamento, lixo, esgoto, caça predatória), mas também impactos socioeconômicos e ético-sociais (violência, desemprego, corrupção, falta de solidariedade e consumismo).

Em relação aos/às alunos/as do Ensino Fundamental e Médio, a maioria atribui ser muito prejudiciais apenas os impactos de natureza ambiental. Os de ordem socioeconômica e éticosociais foram considerados de pouco ou nenhum grau de relação com a degradação do ambiente.

Após a realização do jogo, percebe-se, contudo, uma mudança de postura, acrescentando não apenas as questões ambientais as suas concepções, mas também as dimensões sociais, 
econômicas, culturais e éticas como construtos de desigualdades e degradação ambiental. Embora o contato com o jogo tenha sido limitado a algumas aulas, de acordo com as respostas dos/as aluno/as, percebe-se um processo de sensibilização, etapa inicial para a mudança de postura em direção à sustentabilidade, conforme versa a Carta da Terra.

Sobre quem eram os responsáveis pelos problemas ambientais, a maioria afirmou serem os políticos (vereadores, deputados, senadores), o governo (prefeito, governador e presidente da república) e as pessoas que vivem próximas aos problemas ambientais. Após a aplicação do "RCT Jogo", os/as discentes passaram a conceber como responsável também o próprio "Eu" e não apenas apontando o "outro", a exemplo dos políticos, governo e pessoas que vivem próximo aos problemas.

Os resultados indicam uma posição participativa e corresponsabilizadora dos problemas ambientais, o que remonta o primeiro passo em direção à uma consciência crítica, pois tomaram consciência de sua realidade e de sua posição no mundo, indo em direção ao que Freire (2009) denomina de consciência crítica, na qual o homem e a mulher não estão apenas no mundo, mas com o mundo.

Quando perguntado se os/as professores/as trabalhavam valores como solidariedade, cooperação, consumo consciente, respeito, amor e esperança durante as aulas, metade dos/as alunos/as afirmou que "sim", embora poucos/as conseguiram descrever como eram desenvolvidos tais valores. Entre os/as que disseram que "sim", explicaram que ocorria por meio do respeito ao docente, às pessoas e ao meio ambiente, utilizando como estratégias conversas, vídeos, palestras e exemplos de vida.

Embora muitos alunos/as afirmarem no "pré-teste" que valores como solidariedade, cooperação, entre outros, eram trabalhados em sala de aula, outra metade afirmou que "não", o que nos leva a considerar que conhecer os valores universais não significa vivenciá-los e/ou ter se preocupado em segui-los; todavia, no "RCT Jogo" os/as alunos/as podem não apenas conversar sobre eles, mas vivenciá-los individual e coletivamente. Tal fato torna-se evidente quando, após aplicação, a maioria afirmou que o jogo propiciou uma integração mais efetiva com tais valores, uma vez que vivenciaram momentos individuais, mas que só se concretizavam em relação com $o$ outro.

Em suma, a utilização do "RCT Jogo" demonstrou ser um jogo importante e de natureza lúdica-pegagógica, facilitador do processo de ensino-aprendizagem da Educação Ambiental, além de configurar um elemento de "práxis" educativa, importante ao processo de ressignficação de valores e visões de mundo, como afirma Freire (1980: 26), "a reforma do pensamento inicia-se pela conscientização, pois manifesta-se como um teste de realidade, ou seja, quanto mais conscientização, mais se "dês-vela" a realidade, mais se penetra na essência fenomênica do objeto ao qual encontra-se para analisar". Por essa mesma razão, Scocuglia (1999) reforça que a conscientização não pode existir fora da "práxis", ou melhor, sem o ato ação-reflexão.

\section{Conhecimento e ação: Discutindo a aplicação do Jogo}

O jogo foi aplicado a 18 alunos/as do Ensino Médio, 21 do Ensino Fundamental e 21 da EJA, sendo esse total divisível por 03 ou 06, dependendo da quantidade de alunos/as que joguem. Assim, para o Ensino Médio, os/as 18 alunos/as foram agrupados em 06 grupos de 03, e para o Ensino Fundamental e EJA, os/as 21 representantes de cada nível de ensino foram agrupados em 03 grupos de 07. A intenção de agrupá-los/as consiste primariamente em tornar o jogo adaptável a qualquer número de participantes, bem como ampliar a interação e socialização dos/as envolvidos/as.

A duração do jogo ocorreu de forma diferenciada de acordo com o nível de ensino. No Ensino Fundamental e EJA foram necessárias 03 horas/aula, enquanto que no Ensino Médio apenas 02 horas/aula. Resultados semelhantes foram encontrados na aplicação do jogo "Guardião do Meio Ambiente" nas escolas públicas de Ensino Fundamental e Médio de Campo Grande-MS), na qual foi necessário um tempo maior para os/as alunos/as do Ensino Fundamental (Graciolli-Patriarcha 2009). 
Antes de iniciar o jogo, a temática Educação Ambiental e Carta da Terra foram explicadas por meio de exposição dialogada e apresentação de vídeos educativos. Na sequência as regras foram explicadas e o jogo foi iniciado.

No início, alguns/mas alunos/as ficaram temerosos/as, demonstrando que o jogo não fazia parte de seu cotidiano escolar, mas no decorrer, foram contagiados por uma expressão de entusiasmo e motivação, mesmo para os/as mais tímidos/as. Tais comportamentos demonstraram que os conteúdos abordados no jogo, embora não se tratando do conteúdo programático escolar, eram "apreendidos" por eles/as.

Vygotsky (2001) afirma que a aprendizagem do sujeito é produto da interação que ele realiza com o conhecimento a ser aprendido. Como o jogo simula ações cotidianas, que embora não seja corriqueira no dia-a-dia escolar, tornam-se intrínsecos aos/às participantes por fazer parte de sua realidade.

Com o jogo, os/as alunos/as puderam construir de forma contextualizada, interativa e crítico-reflexiva os quatro princípios da Carta da terra: (1) respeitar e cuidar da comunidade de vida; (2) integridade ecológica; (3) justiça social e econômica; (4) democracia, não violência e paz,encaminhando para o que propõe Miranda (2001), atividades envolvendo jogos facilitam, de forma divertida e prazerosa, o entendimento de conteúdos considerados de difícil aprendizagem.

Igualmente, durante o jogo, foi possível exercitar algumas ações como ouvir, falar, pensar, argumentar e decidir, situações cada vez mais distantes no cotidiano escolar, pois segundo Florentino (2013) sem elas torna-se muito difícil - se não impossível - para entender em toda sua plenitude os princípios da Carta da Terra, uma vez que essas habilidades permitem a troca de experiências, a reflexão e a tomada de decisão.

A dinâmica do jogo apresentou-se como um modelo instigante, capaz de despertar o interesse e o envolvimento dos/as alunos/as com a Carta da Terra, de maneira participativa e relacional, como afirma Guimarães (2004), uma sinergia do "um com o outro" e não apenas do "Eu" separado do "Nós".

Acrescentamos, ainda, que a "práxis" conduzida ao longo das situações vivenciadas pelo jogo podem ser consideradas como um importante passo para a construção de políticas públicas socioambientais, pois possibilita a proposição de alternativas que possam primar por relações sustentáveis que contemplem não apenas o ambiental, mas o social, o cultural, o econômico e o ético, como propõe a Carta da Terra.

Portanto, ao final da aplicação do "RCT Jogo", percebemos que a temática foi abordada conforme propõe a Carta da Terra e a Educação Ambiental Crítica que, além de tratar de assuntos relacionados à proteção e uso racional dos recursos naturais (solo, água, fauna, flora, entre outros), também deve estar focada na proposição de ideias e princípios que possibilitem a construção de valores éticos, sociais e culturais da sustentabilidade socioambiental.

\section{Avaliação do Jogo pelos/as aluno/as}

Procurando identificar se o "RCT Jogo" é viável em sala de aula com alunos/as de diferentes níveis de ensino, após a realização do jogo, foi solicitado que o avaliassem.

Os resultados da avaliação indicam que o jogo atendeu as expectativas dos/as alunos/as: "Foi um jogo muito diferente, muito educativo. Nunca tinha participado deste tipo de jogo." discente do EJA; "É um jogo coletivo que ajudou a conhecer mais o meio ambiente e a agir juntos." - discente do Ensino Fundamental; "Jogo interativo e cheio de situações do dia-a-dia, ajudando no nosso conhecimento de forma dinâmica e prazerosa." - discente do Ensino Médio.

Quanto ao sentimento de participar de um jogo de tabuleiro que não há competição, todos os/as alunos/as (Ensino Fundamental, EJA e Ensino Medio) afirmaram "sentir-se bem": "Feliz. Foi a primeira vez que participo deste tipo de jogo." - discente do EJA; "Me senti como se não existisse vencedores e perdedores." - discente do Ensino Fundamental; "Confortável já que não há intenção de ganhar, de prejudicar alguém, mas de aprender sobre o meio ambiente, de forma prazerosa, sem competição. Todos ajudando um ao outro em um só objetivo." - discente do Ensino Médio. 
Para Piaget, o termo "cooperar" significa "operar junto", jogar com o outro e não contra o outro (Kammi \& Devries 2009). O "RCT Jogo" envolveu os/as alunos/as, independentemente da idade e nível de ensino em virtude de “Ao jogar, não apenas representamos simbolicamente a vida, vamos além. Quando jogamos estamos praticando, direta e profundamente, um Exercício do Co-existência e de Re-conexão com a essência da Vida" (Brotto 2002: 13).

Em relação à interação e regras do jogo, todos/as os/as alunos/as foram unânimes em dizer que as regras eram claras e não necessitava de ajustes, e que proporcionou a interação entre eles/as e o jogo: "Todo mundo jogou e curtiu a disposição do jogo."- discente do EJA; "Eu particularmente amei o jogo, porque todo mundo participou sem que ninguém ficasse fora." discente do Ensino Fundamental; "A turma no inicio estava engessada, com o decorrer do jogo todos se abriram mais, se integrando ao jogo e conhecendo o meio ambiente de forma divertida bem diferente das aulas nos dias normais.” - discente do Ensino Médio.

Por meio do jogo estamos proporcionando momentos de autopercepção, raciocínio e relacionamento interpessoal, fazendo com que no "jogar" sejam praticados, simultaneamente, o movimento, o sentimento e o pensamento (Falcão 2008); ou seja, interação entre os pares (aluno/a-aluno/a) com o jogo (ambiente).

$\mathrm{Na}$ avaliação das dificuldades, mais de $80 \%$ dos/as alunos/as dos três níveis afirmaram não ter dificuldades. Entre os/as que apontaram dificuldades (menos de 20\%), relataram as atividades sensório-motoras como sendo o maior entrave: "Fiquei tímida no início, mas depois me soltei." - discente EJA; "Fiquei com vergonha de realizar algumas tarefas."- discente do Ensino Fundamental"; "Experimentar algo novo, mesmo que bom, nos deixa encabulado." - discente do Ensino Médio.

Por intermédio da avaliação do jogo pelos/as alunos/as, constatamos que o "RCT Jogo" foi apropriado para o contexto escolar, mesmo ocorrendo diferença cronológica e cognitiva, consistindo, portanto, numa estratégia metodológica para o processo ensino-aprendizagem da Educação Ambiental de forma criativa, prazerosa e crítica, pois agrega conhecimento e diversão.

Ao adotarmos o Jogo como uma pedagogia, assumimos o compromisso de recriálo constantemente, visando o exercício crítico-criativo, permitindo àquele que participa do Jogo, conhecer e experimentar, tanto o já existente, como o que ainda está para existir (Brotto 2002: 19).

Ao jogar, o/a aluno/a rompe com as amarras e preconceitos estereotipados pela sociedade, libertando sua capacidade de criação, recriação e reinvenção do mundo, e, portanto, tornando-se atores e protagonistas da construção do conhecimento e de suas relações com o mundo e com os outros.

Entretanto, destacamos que apesar ser eficiente no processo ensino-aprendizagem da Educação Ambiental, "o jogo por si só não é suficiente para justificar mudanças de comportamento perante as questões ambientais" (Carvalho \& Chacur 2012: 283); é necessário, entretanto, o envolvimento de todos/as numa Educação Ambiental Crítica que ultrapasse os “cárceres” do ensino tradicional.

\section{Considerações finais}

O "RCT Jogo" foi bem aceito pelos/as alunos/as e funcionou como um instrumento facilitador da integração, da sociabilidade e desenvolvimento de conhecimentos, atitudes e habilidades necessárias a um processo de ensino e aprendizagem da Educação Ambiental, pautada na práxis de questões socioambientais e ético-culturais.

Constatamos que, por intermédio de jogos cooperativos, torna-se mais fácil envolver os/as alunos/as, pois ao reduzir e/ou eliminar o caráter competitivo, eles/as sentem-se mais à vontade para manifestar seus pensamentos e suas formas de relacionamento com o ambiente e com o ser humano. 
O lúdico proporcionado pelo "RCT Jogo" enriqueceu o ambiente escolar, motivando-os/as a desenvolver habilidades que vão além das motoras e do prazer do jogar por jogar, pois, ao ser administrado em sala de aula, ajudou na construção de uma "consciência crítica", mesmo que em caráter primário, em virtude da troca de ideias e experiências entre os/as participantes, proporcionando um ambiente de intercambio cultural e ético, o que contribui para o fortalecimento das relações sociais e a construção do respeito e da tolerância entre as várias formas de "ser" e "pensar".

O desenvolvimento da atenção e da criatividade também foram habilidades percebidas durante a aplicação do "RCT Jogo". A primeira foi percebida à medida que os/as participantes estavam concentrados em seguir as regras corretamente, bem como no que o outro falava, pois a todo o momento o grupo poderia ser solicitado para ajudar. A segunda esteve presente em todos os momentos em que os/as alunos/as precisavam criar situações problemas que deveriam ser entendidas por todos.

Todas as observações citadas anteriormente corroboram para que o "RCT Jogo" seja entendido como uma estratégia importante no processo de ensino e aprendizagem escolar, pois promove o desenvolvimento das estruturas psicológicas, cognitivas e também sociais; a além de facilitar a assimilação do conteúdo, propicia a construção de habilidades imprescindíveis para a formação de um cidadão social e responsável pelas suas decisões, capaz de compreender, explicar e agir por meio de atitudes críticas e sustentáveis.

Entretanto, alerta-se que o "RCT Jogo" é a apenas um recurso que pode ajudar nesse processo de tomada de consciência; no entanto, não pode ser apenas ele e tampouco uma ação pontual que ressignificará as formas de "pensar" e "agir" da sociedade.

Para um processo de ressignificação dos saberes e fazeres da sociedade é necessário pensar a sustentabilidade não apenas como um processo de transformação de valores e posturas em relação ao ambiente, mas, sobretudo, integrar o social, o cultural e o ético como dimensões inseparáveis e necessárias à construção e/ou reconstrução de uma sociedade sustentável.

\section{Agradecimentos}

Aos revisores anônimos pela revisão crítica do manuscrito.

\section{Referências}

Abuhab P. \& Blauth G. (2011) Jogo de Tabuleiro - a Carta da Terra. Florianópolis: Instituto Harmonia da Terra. $36 \mathrm{p}$.

Bechelli G. (2005) Resgatando os Valores Universais na Educação através dos Jogos Cooperativos. Monografia de especialização, Programa de Pós-Graduação em Jogos Cooperativos, Centro Universitário Monte Serrat, Santos, São Paulo.

Brasil (2006) Educação para a Cidadania: Guião de Educação para a Sustentabilidade: Carta da Terra. Brasília: MEC. 62 p.

Brotto F. O. (2002) Jogos Cooperativos - O Jogo e o Esporte como um Exercício de Convivência. $2^{\circ}$ edição. Santos: Projeto Cooperação. 160 p.

Carta da Terra (2007) A carta da Terra. Disponível em: http://www.mma.gov.br/estruturas/agenda 21/_arquivos/carta_terra.pdf. (Acessado em 16/08/2017).

Carvalho E.M. \& Chacur M.M. (2012) Jogo Ecológico: instrumentação didática na construção de conceitos socioambientais para alunos do ensino básico. Revista Eletrônica Mestrado Educação Ambiental, 28: 274-278.

Dias G.F (2003) Um Grande Desafio: dimensões humanas das alterações globais. (p. 243-254). In: Dias G.F. (Ed.). São Paulo: Gaia. 551 p.

Falcão P. (2008) Criação e Adaptação de Jogos em T \& D. $2^{\circ}$ edição. Rio de janeiro: Qualitymark. $118 \mathrm{p}$. 
Florentino H.S. (2013) Educação Ambiental no Bioma Caatinga: por uma formação continuada de professores no município de Sumé-PB. Dissertação de Mestrado, Programa de PósGraduação em Desenvolvimento e Meio Ambiente, Universidade Federal da Paraíba, João Pessoa, Paraíba.

Freire P (1980) Conscientização: teoria e prática da libertação. São Paulo: Moraes. 116 p.

Freire P. (2009) Educação Como Prática de Liberdade. Rio de Janeiro: Paz e Terra. 150 p.

Gadotti M. (2010) A Carta da Terra na Educação. São Paulo: Editora e Livraria Instituto Paulo Freire. $104 \mathrm{p}$.

Guerra R.A.T. \& Abílio F.J.P. (2006) Educação Ambiental na Escola Pública. João Pessoa: Foxgraf. $146 \mathrm{p}$.

Gil A.C. (2008) Como Elaborar Projetos de Pesquisa. São Paulo: Atlas. 184 p.

Graciolli-Patriarcha S.R. (2009) Jogo "Guardião do Meio Ambiente": uma proposta pedagógica para o ensino de ciências e educação ambiental. Dissertação de Mestrado, Programa de PósGraduação Ensino de Ciências, Universidade Federal de Mato Grosso do Sul, Campo Grande, Mato Grosso do Sul.

Gramigna M.R. (2007) Jogos de Empresas e Técnicas Vivenciais. São Paulo: Pearson Prentice Hall. $160 \mathrm{p}$.

Grun M. (1996) Ética e Educação Ambiental: A conexão necessária. Campinas: Papirus. 123 p.

Guimarães M. (2004) A Formação de Educadores Ambientais. Campinas: Papirus. 174 p.

Jacobi P. (2003) Educação Ambiental, Cidadania e Sustentabilidade. Cadernos de Pesquisa, 1(118): 189-205.

Kammi C. \& Devries R.P. (1991) Jogos em Grupo na Educação Infantil: implicações da teoria de Piaget. São Paulo: Trajetória Cultural. 352 p.

Leff E. (2001) Epistemologia ambiental. São Paulo: Cortez. 240 p.

Loureiro C.F.B. (2007) Educação Ambiental Crítica: contribuições e desafios (p. 66-71). In: Mello S.S. \& Trajber R. (Coord.). Vamos Cuidar do Brasil: conceitos e práticas em educação ambiental na escola. Brasília: MEC/MMA/UNESCO. 248 p.

Miranda S. (2001) No fascínio do jogo, a alegria de aprender. Ciência Hoje, 168(28): 64-66.

Neves M.C.D. \& Pereira R.F. (2006) Divulgando a Ciência: de brinquedos, jogos e do vôo humano. Maringá: LCV edições. $160 \mathrm{p}$

Oliveira V.B. (2004) Jogos de Regras e a Resolução de Problemas. $2^{\circ}$ edição. Petrópolis: Vozes. 92 p.

Richardson R.J. (2007) Pesquisa Social: métodos e técnicas. $3^{\circ}$ edição. São Paulo: Atlas. 334 p.

Scocuclia A.C. (1999) A História das Ideias de Paulo Freire e a atual crise de paradigmas. João Pessoa: UFPB/ Ed. Universitária. 205 p.

Triviños A.N.S (2009) Introdução à Pesquisa em Ciências Sociais: a pesquisa qualitativa em educação. São Paulo: Atlas. 175 p.

Tuan Y. (2012) A Topofilia: um estudo da percepção, atitudes e valores do meio ambiente. Londrina: EDUEL. 342 p.

Vasconcellos C.S. (2004) Construção do Conhecimento em Sala de Aula. São Paulo: Libertad. 144 p.

Vygotsky L.S. (2001) A Construção do Pensamento e da Linguagem. São Paulo: Martins Fontes. $487 \mathrm{p}$. 